\title{
HCI for Peace: Promoting Peace and Preventing War through Computing Technology
}

\author{
Juan Pablo Hourcade ${ }^{1}$, Natasha E. Bullock-Rest ${ }^{1}$, Janet C. Read ${ }^{2}$, and Yoram Chisik ${ }^{3}$ \\ ${ }^{1}$ University of Iowa, \\ Iowa City, IA 52242 USA \\ ${ }^{2}$ University of Central, Lancashire, \\ Preston, PR1 2HE UK \\ ${ }^{3}$ Universidade da Madeira, \\ 9020-105 Funchal, Portugal \\ juanpablo-hourcade@uiowa.edu, natasha.bullock.rest@gmail.com, \\ jcread@uclan.ac.uk, ychisik@gmail.com
}

\begin{abstract}
Our aim in this SIG is to discuss the role human-computer interaction can play in bringing about peace by influencing socio-economic factors that affect the likelihood of conflict as well personal values involved in making decisions to support conflict.
\end{abstract}

Keywords: Peace, war, pervasive computing, conflict.

\section{Introduction}

The increasing pervasiveness of computing devices provides human-computer interaction researchers with new opportunities to influence socio-economic and personal factors that affect the likelihood of war and peace. With this in mind, we have started an initiative called HCI for Peace to highlight and celebrate research with peace as its explicit goal. We also hope to form a community of researchers with an interest in using computing technologies to promote peace and prevent war in order to coordinate efforts, share ideas and have a greater impact. Our world can be no brighter than the worlds we dream of.

We have already begun building a community through activities at the CHI conference. During CHI 2010, 500 attendees wore peace ribbons on their name badges and engaged in discussions with others on the role human-computer interaction can play in promoting peace and preventing conflict. During CHI 2011, we are scheduled to present a full paper with a call for constructive action on peace [1], and we will also have a panel discussion. In addition, we have setup a website at hciforpeace.org where we feature interviews and stories on human-computer interaction research for peace.

The INTERACT conference provides us with a unique opportunity to extend our discussions and our community internationally. Through a SIG, we expect to be able to gain new perspectives and bring more voices into the community. 


\section{Why Peace?}

Peace is a very practical goal to pursue. One reason for this is that war is very expensive. For example, the United States spends roughly 2 billion USD every week on the conflicts in Iraq and Afghanistan [4]. War can also have a devastating economic impact on poorer countries, with most of the poorest countries in the world currently or recently involved in armed conflicts [3]. The most horrible costs though are in terms of human lives, and in the trauma inflicted on those who survive.

\section{Discussion}

In our previous work [1], we have approached the topic of peace and conflict by reviewing empirical studies on the causes of armed conflict at a socio-economical level. We have also looked into research on moral decisions at a personal level and how these can affect decisions to support war or to kill in the battlefield. Based on this review we have identified human-computer interaction research that is already being conducted and that could be conducted to positively affect both socio-economic factors and personal decisions. Recent events have made these discussions more concrete, with computer technologies, for example, playing a crucial role in (mostly peacefully) toppling dictatorships in Egypt and Tunisia earlier this year [2]. Hosting a SIG will enable us to get new perspectives and discuss alternative ways of approaching research on peace.

A SIG will also be an opportunity to discuss some difficult questions. For example, what role can human-computer interaction realistically play in conflict prevention and resolution? How can we measure the effect of projects on peace and conflict? How can we identify the best situations in which computing technologies can play a positive role? How do we address multiple perspectives during a conflict? We hope these questions will generate fruitful discussions and produce useful ideas.

\section{References}

1. Hourcade, J.P., Bullock-Rest, N.E.: HCI for Peace: A Call for Constructive Action. In: Proceedings of CHI 2011, pp. 443-452. ACM Press, New York (2011)

2. Khan, A., Haddad, H., Maher, K., Dubner, R.: Lessons Learned from the Arab Spring Revolutions. In: South by Southwest Conference (2011), http: //schedule.sx.sw.com/event.s/event_IAP000461

3. Stewart, F.: Root causes of violent conflict in developing countries. BMJ 324, 342-345 (2002)

4. Stiglitz, J.E., Bilmes, L.J.: The Three Trillion Dollar War: The True Cost of the Iraq Conflict. Norton, New York (2008) 